\title{
The state of charge estimation of lithium-ions battery using combined multi-population genetic algorithm - BP and Kalman filter methods
}

\author{
Qingyun Ma, Chuanyun Zou, Shunli Wang, Jingsong Qiu
}

School of Information Engineering, Southwest University of Science and Technology (SWUST), Mianyang, Sichuan, China, 621010

*E-mail: zou_cy@qq.com

Received: 1 November 2021 / Accepted: 26 November 2021 / Published: 5 January 2022

\begin{abstract}
Accurate estimation of state of charge (SOC) of lithium-ion batteries is the core technology of battery management system and the key to prolong battery life. However, it is difficult to estimate SOC accurately online and the estimation accuracy is not high. Taking ternary lithium battery as the research object, a Back-Propagation (BP) neural network optimized by multi-population genetic algorithm (MPGA) is proposed to compensate the nonlinear errors caused by EKF in the process of linearization and to avoid genetic algorithm (GA) immature phenomenon. The BP neural network optimized by MPGA is used to predict the EKF error at $\mathrm{k}$ time, so as to compensate the nonlinear error at extended Kalman K time. Adaptive FFRLS is used to identify model parameters, so that the algorithm can be identified online. The accuracy range of the proposed algorithm is less than 0.0121 verified by dynamic stress testing (DST) results, and the maximum error and average error are small. The proposed algorithm can track the theoretical value of SOC more effectively, and the SOC estimated by the proposed algorithm is stable.
\end{abstract}

Keywords: State of charge; Multi-population genetic algorithm; Adaptive FFRLS; Lithium-ion batteries

\section{FULL TEXT}

(C) 2022 The Authors. Published by ESG (www.electrochemsci.org). This article is an open access article distributed under the terms and conditions of the Creative Commons Attribution license (http://creativecommons.org/licenses/by/4.0/). 